\title{
Synthesis of Strontium Oxide Whiskers with Preferential $<111>$ Orientation by Atmospheric Chemical Vapor Deposition
}

\author{
Keiji Komatsu ${ }^{1}$, Morito Tanabe ${ }^{1}$, Ikumi Toda ${ }^{1}$, Shigeo Ohshio ${ }^{1}$, Hiroyuki Muramatsu ${ }^{1}$ \& Hidetoshi Saitoh ${ }^{1}$ \\ ${ }^{1}$ Department of Materials Science and Technology, Nagaoka University of Technology, Japan \\ Correspondence: Keiji Komatsu, Department of Materials Science and Technology, Nagaoka University of \\ Technology, 1603-1 Kamitomioka, Nagaoka, Niigata 940-2188, Japan. Tel: 81-258-479-379 E-mail: \\ Keiji_Komatsu@mst.nagaokaut.ac.jp
}

Received: December 14, 2015 Accepted: January 19, 2016 Online Published: January 31, 2016

doi:10.5539/jmsr.v5n2p50

URL: http://dx.doi.org/10.5539/jmsr.v5n2p50

\begin{abstract}
Highly oriented strontium oxide ( $\mathrm{SrO}$ ) whiskers were obtained using a chemical vapor deposition technique at atmospheric pressure. The $\mathrm{SrO}$ whiskers were synthesized on a single-crystalline $\mathrm{Si}(100)$ substrate from strontium bis-dipivaloylmethanate, $\operatorname{Sr}\left(\mathrm{C}_{11} \mathrm{H}_{19} \mathrm{O}_{2}\right)_{2}$. The presence of face-centered cubic (fcc) SrO structures was confirmed. The hexagonal $\mathrm{SrO}$ whiskers were preferentially oriented in the $<111>$ direction upon increasing deposition time. This phenomenon is based on equilibrium figure in the $<111>$ direction of fcc crystals.
\end{abstract}

Keywords: oxides, strontium oxide, chemical vapor deposition (CVD), atmospheric CVD, crystal growth, whisker

\section{Introduction}

Strontium oxide $(\mathrm{SrO})$ is a fine-ceramic material with a wide range of applications. It is expected to be useful both in electronic devices and as a phosphor material. For example, SrO has a small work function of $1.27 \mathrm{eV}$. This low value makes it possible to apply SrO materials as Electron-inducing buffer layers in organic electric luminescence (EL) devices (Kim, et al., 2000; Tanaka et al., 2003). SrO has shown blue luminescence at $456 \mathrm{~nm}$ when $\mathrm{Eu}^{2+}$ ions are present, acting as emission centers (Komatsu \& Shirai, 2013; Komatsu \& Nakamura, 2013). SrO is also used as a buffer layer for the crystal growth of perovskite-type oxides such as $\mathrm{BaSrTiO}_{3}(\mathrm{BST})$ and $\mathrm{SrTiO}_{3}(\mathrm{STO})$ (Kosola et al., 2003). BST and STO show high-temperature superconductivity and ferroelectricity, properties of interest for Dynamic Random Access Memory (DRAM) applications.

Syntheses of $\mathrm{SrO}$ films have been reported by various researchers because of the potential applications for these materials. For example, SrO films were obtained on a $\mathrm{SiO}_{2} / \mathrm{Si}(100)$ substrate using an atomic layer deposition (ALD) method, from bis(triisopropylcyclopentadienyl) strontium (Zhang et al., 2011). J. Pena reported producing a $\mathrm{SrO}-\mathrm{SrCO}_{3}$ film from bis(2,2,6,6-tetramethylheptane-3,5-dionato) strontium and strontium bisdipivaloylmethanate, $\operatorname{Sr}(\mathrm{DPM})_{2}$, by aerosol-assisted metalorganic chemical vapor deposition (Pena et al., 1997). These methods require vacuum equipment and are costly. Atmospheric chemical vapor deposition techniques can also be used for metal oxide film synthesis. In atmospheric CVD, metal-containing organic complexes are used as metal sources for oxide films. For examples, bis-magnesium acetylacetonate can be used as the $\mathrm{Mg}$ source for $\mathrm{MgO}$ films (Saitoh, Okada, \& Ohshio, 2002) and titanium tetraisopropoxide (TTIP) can provide Ti for $\mathrm{TiO}_{2}$ films (Tokita et al., 2003), using atmospheric CVD techniques. The atmospheric CVD setup is, fundamentally, a thermal CVD type. It enables the design of microarchitectures (of metal oxide crystallites), epitaxy and non-epitaxy processes with high growth rates, and operation without a vacuum system, all at low cost. Hence, highly crystalline $\mathrm{SrO}$ films are expected to be synthesized using atmospheric CVD techniques from metal-containing organic complexes such as $\operatorname{Sr}(\mathrm{DPM})_{2}$.

In this experiment, randomly oriented $\mathrm{SrO}$ films and highly oriented $\mathrm{SrO}$ whiskers were synthesized using an atmospheric CVD technique. The surface morphologies, as well as crystal structures of the SrO materials are described and discussed.

\section{Experimental Work}

Polycrystalline films and whiskers of SrO were prepared using an atmospheric CVD apparatus, shown in Figure 1. First, single crystalline (100) silicon substrates were prepared. Next, the reactant, strontium 
bis-dipivaloylmethanate $\left(\mathrm{Sr}\left(\mathrm{C}_{11} \mathrm{H}_{19} \mathrm{O}_{2}\right)_{2},\left(\mathrm{Sr}(\mathrm{DPM})_{2}\right)\right.$ KOJUNDO CHEMICAL LABORATORY CO., LTD) was loaded into a vaporizer and vaporized using an electric heater. The reactant vapor was first carried by nitrogen gas flowing at a rate of $5 \mathrm{~L} / \mathrm{min}$ then sprayed from a metallic nozzle directly onto substrates mounted on an electric heater. The distance from the nozzle to the substrate was maintained at $15 \mathrm{~mm}$. Other experimental parameters were defined as discussed below. The temperature inside the vaporizer was measured using a K-type thermocouple and is denoted as vaporizing temperature (Tv). In addition, the surface temperature was measured using a K-type thermocouple and is denoted as substrate temperature (Ts). In this study, the effects of Tv, Ts, and deposition duration $(\mathrm{t})$ on $\mathrm{SrO}$ film production were investigated in order to optimize growth conditions for $\mathrm{SrO}$ films synthesized on Si substrates by atmospheric CVD. First, the reactant was heated to $240,260,280$, and $300{ }^{\circ} \mathrm{C}$ (Tv $=240-300{ }^{\circ} \mathrm{C}$ ) while Ts and $\mathrm{t}$ were maintained at $650{ }^{\circ} \mathrm{C}$ and $60 \mathrm{~min}$, respectively. Second, Ts values of 500 or $650{ }^{\circ} \mathrm{C}$ where used while $\mathrm{Tv}$ and $\mathrm{t}$ were maintained at $300{ }^{\circ} \mathrm{C}$ and $60 \mathrm{~min}$, respectively. Thirdly, the $\mathrm{t}$ values of 1 , $5,10,30$, and $60 \mathrm{~min}$ where used while $\mathrm{Ts}$ and $\mathrm{Tv}$ were maintained at 300 and $650{ }^{\circ} \mathrm{C}$ respectively.

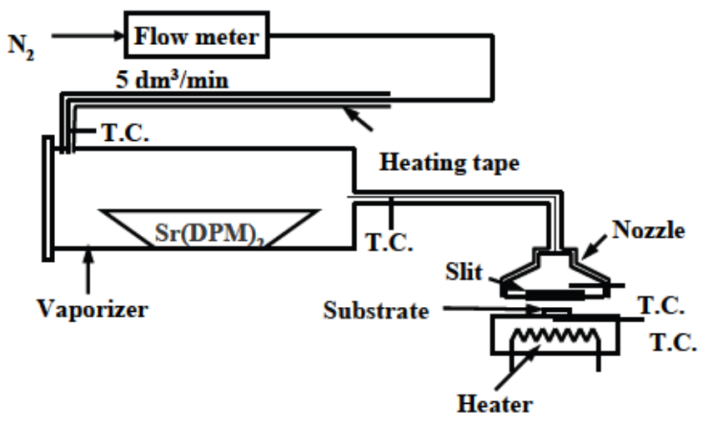

Figure 1. Schematic of atmosphere CVD apparatus

\section{Characterization}

X-ray diffraction (XRD, MO3XHF, Mac Science Co., Ltd.) analysis was used to determine sample crystal structure and growth direction. Film morphologies were observed by scanning electron microscopy (SEM, JSM6700F, JEOL).

\section{Results}

\subsection{Crystal Structure}

$\operatorname{Sr}(\mathrm{DPM})_{2}$ decomposes at temperatures above $200{ }^{\circ} \mathrm{C}$ under $\mathrm{N}_{2}$ (Ryu et al., 2000). $\operatorname{The} \operatorname{Sr}(\mathrm{DPM})_{2}$ conditions in this study had a melting point of $210{ }^{\circ} \mathrm{C}$ and a boiling point of $231{ }^{\circ} \mathrm{C}$ (at $13.3 \mathrm{~Pa}$ ). In this study, metal oxide film depositions of $\operatorname{Sr}(\mathrm{DPM})_{2}$ were achieved by atmospheric CVD. Tv values were varied to determine the optimal vaporization temperature for the $\operatorname{Sr}(\mathrm{DPM})_{2}$ reactant used. XRD patters of films deposited on Si substrates at various Tv values are shown in Figure 2. These pattern confirm the presence of SrO (ICDD card No. 00-006-0520) and $\mathrm{SrCO}_{3}$ (ICDD card No. 00-006-0520) crystalline phases. The diffraction peaks of SrO became more prominent with increasing Tv. In contrast, the existence of SrO crystals could not be confirmed for $\mathrm{Tv}=240{ }^{\circ} \mathrm{C}$. Tv $=300{ }^{\circ} \mathrm{C}$ was the maximum setting available for the atmospheric CVD equipment used. Therefore, the optimal Tv value for $\mathrm{SrO}$ film deposition from vaporized $\operatorname{Sr}(\mathrm{DPM})_{2}$ was $300{ }^{\circ} \mathrm{C}$. Crystallite diameters increase with increasing substrate heating temperature. To investigate the effects of substrate heating temperature, we set Ts to 500 and $650{ }^{\circ} \mathrm{C}$. XRD patterns obtained from the films deposited at different Ts values are shown in Figure 3. Peak assignments according to ICDD cards indicated that both films contained both $\mathrm{SrO}$ and $\mathrm{SrCO}_{3}$ crystalline phases. The fraction of $\mathrm{SrO}$ increased with increasing $\mathrm{Ts}$, as shown in Figure 2. Therefore, SrO production was improved by increasing both Tv and Ts. The crystal structures and morphologies of the films obtained by atmospheric CVD were also sensitive to deposition duration (Tanaka et al., 1997). The atmospheric CVD process used enabled various metal oxide films, with different crystal structures and morphologies, to be produced. We, therefore, investigated the effects of deposition duration on crystal structure and morphology. XRD patterns for films deposited on Si substrate over various deposition durations are shown in Figure 4. The existence of $\mathrm{SrO}$ and $\mathrm{SrCO}_{3}$ crystalline structures was confirmed when deposition durations of more than 10 min were used. Specially, crystalline SrO diffraction peaks were the most prominent in the XRD patterns obtained. In contrast, no diffraction lines indexed to either $\mathrm{SrO}$ or $\mathrm{SrCO}_{3}$ were observed in XRD patterns of samples obtained from deposition durations of 1 and $5 \mathrm{~min}$. 


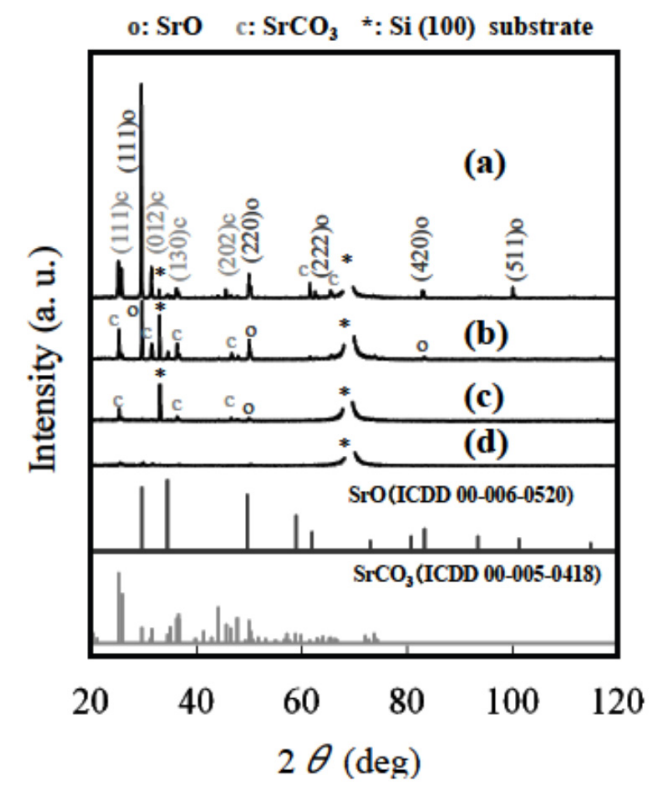

Figure 2. XRD patterns of film deposited on $\operatorname{Si}(100)$ substrates at various vaporizing temperatures $\left(T_{v}\right)$ : (a) $300^{\circ} \mathrm{C}, \quad$ (b) $280^{\circ} \mathrm{C}$, (c) $260^{\circ} \mathrm{C}$, and (d) $240^{\circ} \mathrm{C}$

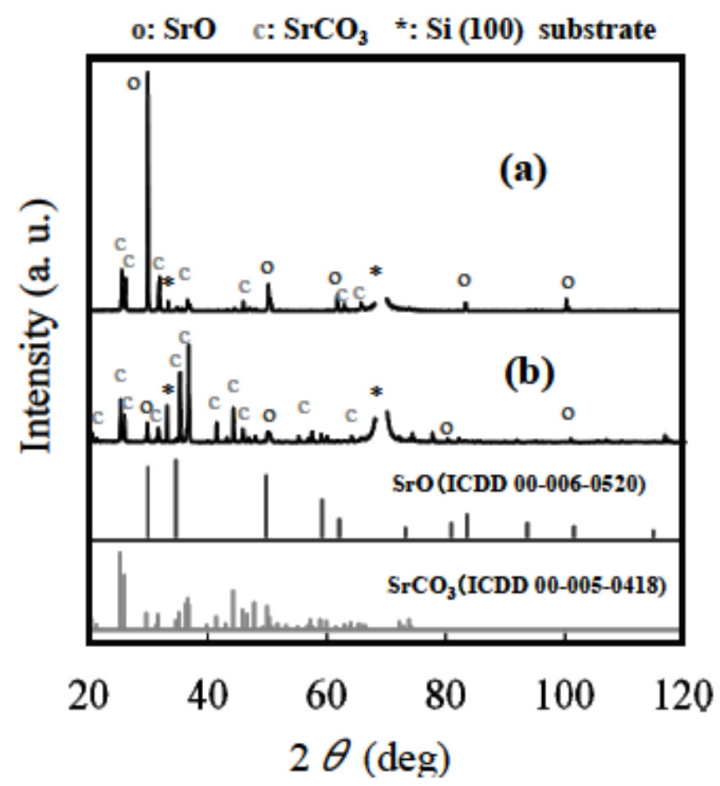

Figure 3. XRD profiles of films deposited on $\mathrm{Si}(100)$ substrates at various substrate temperatures $\left(T_{s}\right)$ : (a) $650^{\circ} \mathrm{C}$, and (b) $500^{\circ} \mathrm{C}$

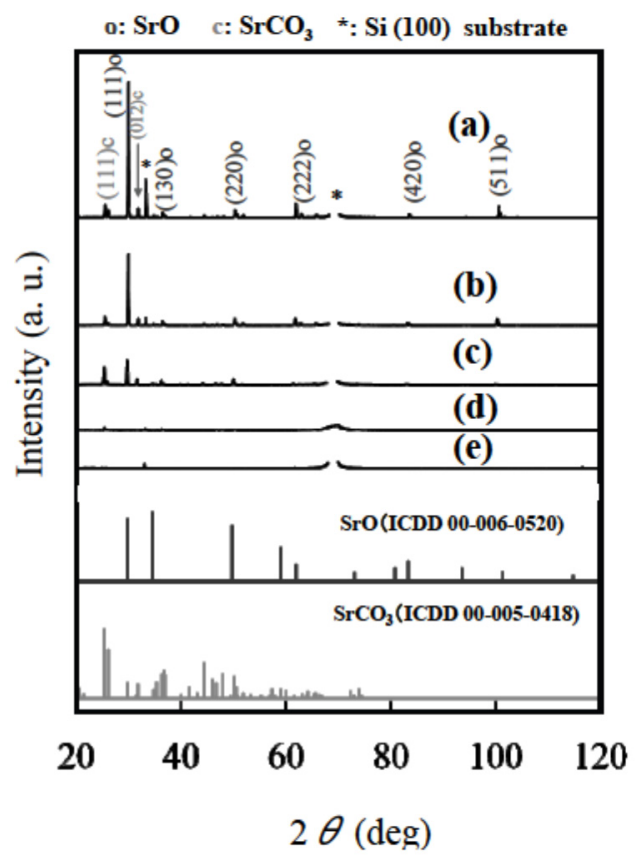

Figure 4. XRD profiles of films deposited on $\operatorname{Si}(100)$ substrates for various durations $(t)$ : (a) $60 \mathrm{~min}$, (b) $30 \mathrm{~min}$, (c) $10 \mathrm{~min}$, (d) $5 \mathrm{~min}$, and (e) $1 \mathrm{~min}$

\subsection{Morphological Study}

Micrographs of the surfaces of the obtained SrO films are shown in Figure 5, as is an image of the Si substrate, alone, for comparison. Surface morphologies of the obtained films varied with deposition durations. Crystallite size increased with increasing deposition duration. Notably, $\mathrm{SrO}$ whiskers, with hexagonal, star-like morphologies were observed, as shown in Figure 5 (a). Figure 6 shows cross-sectional SEM micrographs of films deposited on $\mathrm{Si}(100)$ substrates. The $\mathrm{SrO}$ whiskers were existed randomly on single crystalline silicon substrate. SrO whisker 
have length with approximately 1-3 $\mu \mathrm{m}$. In contrast, densfied SrO film with $1 \mu \mathrm{m}$ thickness were observed in Figure 6(b). The SrO whiskers with a unique film morphology were synthesized by atmospheric CVD using a deposition duration of $60 \mathrm{~min}$. In related previous reports, $\mathrm{ZnO}$ :Al whiskers, obtained by atmospheric CVD, were shown to be suitable for application as field emission emitters (Ueda et al., 2008). Moreover, higher current densities were realized by adding carbon-related materials (a-C:H films, a-CNx) to the surfaces of $\mathrm{ZnO}: \mathrm{Al}$ whiskers (Ohkawara et al., 2001). Work function values for these carbon related materials were easily controlled using termination structures (Satioh et al., 2002). Hence, the SrO whiskers, obtained here, show potential as future functional materials.

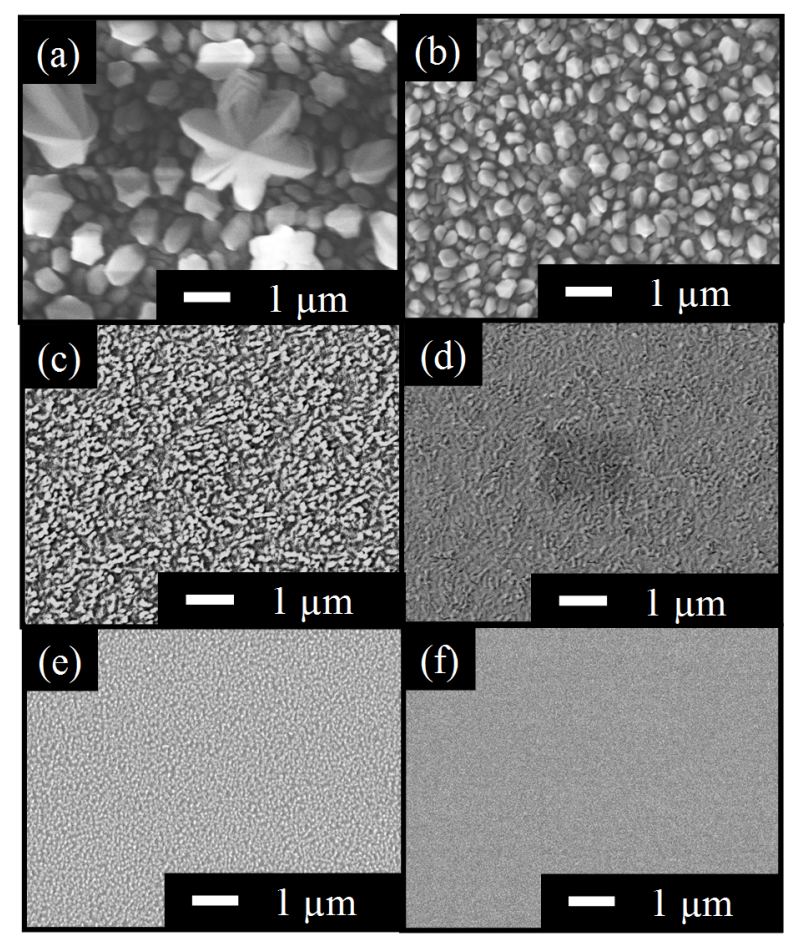

Figure 5. Surface SEM micrographs of films deposited on $\operatorname{Si}(100)$ substrates for various durations $(t)$ : (a) $60 \mathrm{~min}$, (b) $30 \mathrm{~min}$, (c) $10 \mathrm{~min}$, (d) $5 \mathrm{~min}$, (e) $1 \mathrm{~min}$ and (f) $0 \mathrm{~min}$

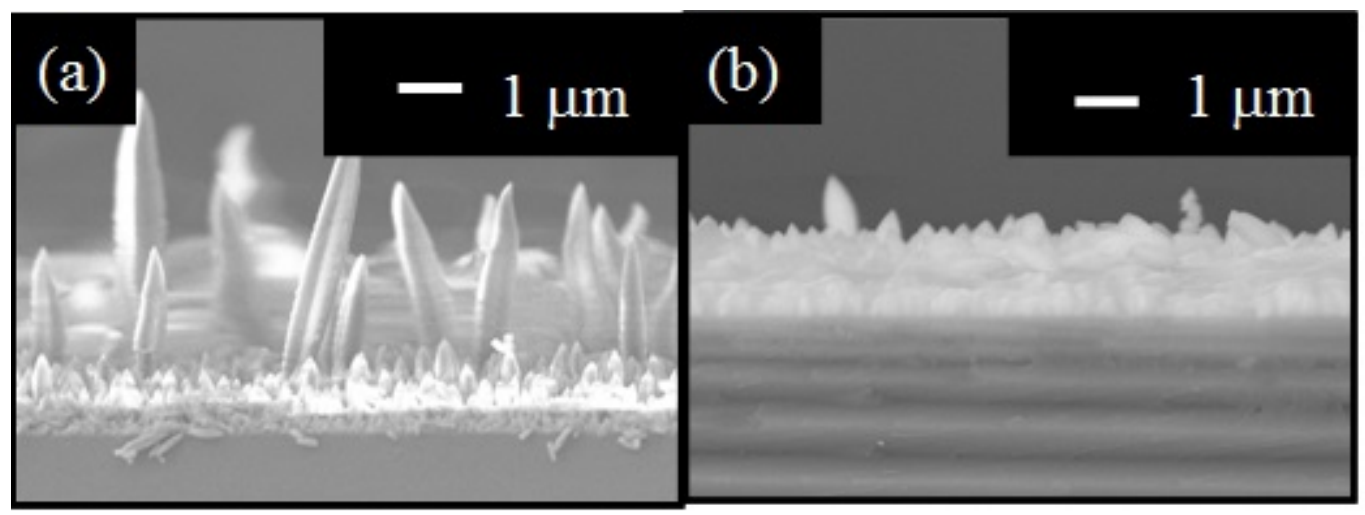

Figure 6. Cross-sectional SEM micrographs of films deposited on Si(100) substrates for various durations $(t)$ : (a) $60 \mathrm{~min}$, (b) $30 \mathrm{~min}$ 


\section{Discussion}

Below we discuss the deposition process for $\mathrm{SrO}$ films from a $\mathrm{Sr}(\mathrm{DPM})_{2}$ precursor by atmospheric CVD. Firstly, the $\operatorname{Sr}(\mathrm{DPM})_{2}$ was vaporized at $300^{\circ} \mathrm{C}$. The vaporized reactant was carried by flowing nitrogen gas and immediately thermally decomposed upon contact with the heated substrate. During the thermal decomposition process of $\operatorname{Sr}(\mathrm{DPM})_{2}$, activated $\mathrm{Sr}$ atoms were liberated by the breakage of $\mathrm{Sr}-\mathrm{O}$ bonds of $\mathrm{Sr}(\mathrm{DPM})_{2}$ (Keltsusyoseityou, 2003). These activated $\mathrm{Sr}$ atoms reacted with $\mathrm{O}_{2}$ and $\mathrm{CO}_{2}$ gases in the air to form $\mathrm{SrO}$ and $\mathrm{SrCO}_{3}$ molecules, by equation (1)

$$
\mathrm{Sr}(\mathrm{DPM})_{2} \rightarrow \mathrm{SrO}+\mathrm{SrCO}_{3} \cdot \cdots \cdot
$$

Next, nucleation of $\mathrm{SrO}$ and $\mathrm{SrCO}_{3}$ occurred at the substrate. Nucleation progressed to the subsequent formation of islands on the substrate and, hence, formation of $\mathrm{SrO}$ and $\mathrm{SrCO}_{3}$ crystals occurred. The obtained $\mathrm{SrO}$ films were star-shaped, hexagonal whiskers. This unique morphology originated from an equilibrium figure in the $<111>$ direction of fcc crystals. Figure 6 shows that equilibrium figure. The hexagonal $\{111\}$ planes were confirmed in fcc crystal (Figure 7(a)). SrO is an fcc crystal with cubic structures. The star-shaped, hexagonal $\mathrm{SrO}$ whiskers were synthesized on the Si substrate based on the equilibrium forms rules (Figure 7(b)). Crystalline phases of $\mathrm{SrO}$ grew along the $<111>$ directions. Thus, SrO whiskers, preferentially oriented in the $<111>$ direction, were synthesized by atmospheric chemical vapor deposition.
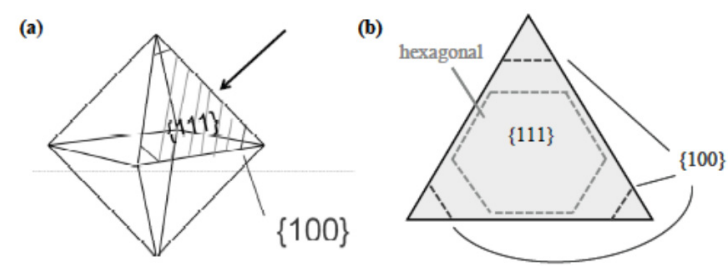

Figure 7. Equilibrium shape of the fcc crystal (a) and a magnified view, from the $<111>$ direction

\section{Conclusion}

Oriented strontium oxide $(\mathrm{SrO})$ whiskers were synthesized at atmospheric pressure. The whiskers were synthesized on single-crystalline $\mathrm{Si}(100)$ substrates from $\operatorname{Sr}(\mathrm{DPM})_{2}$ using an atmospheric chemical vapor deposition (CVD) technique. Highly symmetrical, hexagonal SrO whiskers were obtained on the Si substrate. The structure of these whiskers was based on equilibrium figure in the $<111>$ direction of fcc crystals. Hence, $<111>$-oriented $\mathrm{SrO}$ whiskers were obtained by atmospheric CVD.

\section{References}

Kim, R., Kim, Y., Cho, J., \& Park, J.-W. (2000). Luminous efficiency and secondary electron emission characteristics of alternating current plasma display panels with $\mathrm{MgO}-\mathrm{SrO}-\mathrm{CaO}$ protective layers. Journal of Vacuum Science \& Technology A, 18, 2493-2496. http://dx.doi.org/10.1116/1.1287151

Tanaka, K., Miyagawa, E., \& Usui, H. (2003). Fabrication of electroluminescent devices using Sr as an electron injection layer.Electronics and Communications in Japan Part 2 86, 36-41.

Komatsu, K., Shirai, T., Nakamura, A., Kato, A., Ohshio, S., Nambu, N., ... Saitoh, H., (2013). Synthesis and luminescence properties of $\mathrm{Eu}^{2+}$-doped 8-coordinated $\mathrm{SrO}$ phosphors. Ceramic International 39, 7115-7118.http://dx.doi.org/10.1016/j.ceramint.2013.02.053

Komatsu, K., Nakamura, A., Ohshio, S., Toda, I., Muramatsu, H., \& Saitoh, H. (2013). Optical and structural stability of blue SrO: $\mathrm{Eu}^{2+}$ phosphor. Journal of Solid State Chemistry 204, 186-189. http://dx.doi.org/10.1016/j.jssc.2013.05.015.

Kosola, A., Putkonen, M., Johansson, L.-S., \& Niinisto, L. (2003). Effect of annealing in processing strontium titanate thin films by ALD. Applied Surface Science 211, 102-112. http://dx.doi.org/10.1016/S0169 $-4332(03) 00175-2$

Zhang, C. B., Wielunski, L., \& Willis, B. G. (2011). Formation of strontium template on $\mathrm{Si}\left(\begin{array}{ll}1 & 0\end{array}\right)$ by atomic layer deposition. Applied Surface Science 257, 4826-4830. http://dx.doi.org/ 10.1016/j.apsusc.2010.12.098 
Pena, J., Martlnez, A., Conde, F., -Calbet, J. M. G., \& Vallet-Regi, M. (1997). In situ growth of $\mathrm{SrTiO}_{3}$ thin films prepared by AACVD from strontium and titanium oxide bisdipivaloylmethanates. Solid State Ionics 101-103, 183-190. http://dx.doi.org/ 10.1016/S0167-2738(97)84029-5

Saitoh, H., Okada, Y., \& Ohshio, S. (2002). Synthesis of MgO/ZnO hetero-epitaxial whiskers using chemical vapor deposition operated under atmospheric pressure. Jounral of Materiral Science 37, 4597-4602. http://dx.doi.org/ 10.1023/A:1020696215411

Tokita, S., Tanaka, N., Ohshio, S., \& Saitoh, H. (2003). Photo-induced Surface reaction of highly oriented anatase polycrystalline films synthesized using a CVD apparatus operated in atmospheric regime, Journal of the Ceramic Society of Japan 111, 433-435. http://doi.org/10.2109/jcersj.111.433.

Ryu, H. K., Heo, J. S. , Cho, S. -I., Chung, C., \& Moon, S. H. (2000). Thermal Decomposition Mechanism of $\operatorname{Sr}(\mathrm{DPM})_{2}$. Journal of The Electrochemical Society 147, 1130-1135. http://dx.doi.org/10.1149/1.1393324

Tanaka, N., Ohshio, S., \& Saitoh, H. (1997). Preferential orientation of titanium dioxide polycrystalline films using atmospheric CVD technique.Jounral of Ceramic Society of Japan 105, 551-554. http://doi.org/10.2109/jcersj.105.551

Ueda, Y., \& Saitoh, H. (2008). Field-Emission Properties of Al:ZnO Whisker Emitters with Various Crystallite Lengths and Densities. Japanese Journal of Applied Physics 47, 1584-1588. http://doi.org/10.1143/ JJAP. 475472 .

Ohkawara, Y., Naijo, T., Washio, T., Ohshio, S., Ito, H., \& Saitoh, H. (2001). Field Emission Property of Al:ZnO Whiskers Modified by Amorphous Carbon and Related Films. Japanese Journal of Applied Physics 40, 7013-7017. http://dx.doi.org/10.1143/JJAP.40.7013

Saitoh, H., Akasaka, H., Washio, T., Ohkawara, Y., Ohshio, S., \& Ito, H. (2002). Work Function of Amorphous Carbon Nitride with Various Functional Groups. Japanese Journal of Applied Physics 41, 6169-6173 (2002). http://dx.doi.org/ 10.1143/JJAP.41.6169

Keltusyouseityou. (2003). UCHIDA ROKAKUHO PUBLISHING CO., LTD, 59 (2003). (in Japanese)

\section{Copyrights}

Copyright for this article is retained by the author(s), with first publication rights granted to the journal.

This is an open-access article distributed under the terms and conditions of the Creative Commons Attribution license (http://creativecommons.org/licenses/by/3.0/). 